\title{
Patients over 65 years with Acute Complicated Calculous Biliary Disease are Treated Differently-Results and Insights from the ESTES Snapshot Audit
}

\author{
Gary A. Bass ${ }^{1,2,3}$ - Amy E. Gillis ${ }^{3} \cdot$ Yang Cao $^{4} \cdot$ Shahin Mohseni $^{2,5} \cdot$ for the European Society for \\ Trauma and Emergency Surgery (ESTES) Cohort Studies Group
}

Accepted: 12 February 2021/Published online: 3 April 2021

(C) The Author(s) 2021

\begin{abstract}
Background Accrued comorbidities are perceived to increase operative risk. Surgeons may offer operative treatments less often to their older patients with acute complicated calculous biliary disease (ACCBD). We set out to capture ACCBD incidence in older patients across Europe and the currently used treatment algorithms.

Methods The European Society of Trauma and Emergency Surgery (ESTES) undertook a snapshot audit of patients undergoing emergency hospital admission for ACCBD between October 1 and 31 2018, comparing patients under and $\geq 65$ years. Mortality, postoperative complications, time to operative intervention, post-acute disposition, and length of hospital stay (LOS) were compared between groups. Within the $\geq 65$ cohort, comorbidity burden, mortality, LOS, and disposition outcomes were further compared between patients undergoing operative and nonoperative management.

Results The median age of the 338 admitted patients was 67 years; 185 patients $(54.7 \%)$ of these were the age of 65 or over. Significantly fewer patients $\geq 65$ underwent surgical treatment $(37.8 \%$ vs. $64.7 \%, p<0.001)$. Surgical complications were more frequent in the $\geq 65$ cohort than younger patients, and the mean postoperative LOS was significantly longer. Postoperative mortality was seen in $2.2 \%$ of patients $\geq 65$ (vs. $0.7 \%, p=0.253$ ). However, operated elderly patients did not differ from non-operated in terms of comorbidity burden, mortality, LOS, or postdischarge rehabilitation need.

Conclusions Few elderly patients receive surgical treatment for ACCBD. Expectedly, postoperative morbidity, LOS, and the requirement for post-discharge rehabilitation are higher in the elderly than younger patients but do not differ from elderly patients managed non-operatively. With multidisciplinary perioperative optimization, elderly patients may be safely offered optimal treatment.

Trial Registration ClinicalTrials.gov (Trial \# NCT03610308).
\end{abstract}

Study Collaborators listed in Appendix 1.

Supplementary Information The online version contains

supplementary material available at https://doi.org/10.1007/s00268-

021-06052-0.

Shahin Mohseni

mohsenishahin@yahoo.com; shahin.mohseni@oru.se

Gary A. Bass

garybassmd@gmail.com

Amy E. Gillis

gillisa@tcd.ie
Yang Cao

yang.cao@oru.se

Division of Traumatology, Emergency Surgery \& Surgical Critical Care, Penn Presbyterian Medical Center, University of Pennsylvania, Philadelphia, PA 19104, USA 


$\begin{array}{ll}\text { Abbreviations } \\ \text { AAST } & \begin{array}{l}\text { American Association for the Surgery of } \\ \text { Trauma }\end{array} \\ \text { aaCCI } & \begin{array}{l}\text { Age-adjusted Charlson comorbidity index } \\ \text { Acute Complicated Calculous Biliary } \\ \text { ACCBD }\end{array} \\ \text { Disease } \\ \text { Canadian Study of Health and Aging Frailty } \\ \text { Index }\end{array}$

biliary calculous conditions were older than this teaching suggests, with a median age of 67 years [17, 18].

Despite consensus in several guidelines, surgical practice patterns regarding older patients with ACCBD appear to vary between centers and even between individual surgeons $[17,18]$. This prospective non-randomized observational cohort study aims to provide granular real-world data contrasting outcomes in patients over and under 65 years of age and comparing outcomes following operative and non-operative treatment strategies in patients over 65. Learnings from these data are presented as hypothesis-generating to stimulate further work investigating why definitive surgical therapy is not routinely offered to older patients and to create a context for practice management guidelines.

\section{Methods}

\section{Study centers and patients}

\section{Introduction}

The number of older people undergoing emergency noncardiac surgical procedures over the last 25 years has exceeded the rate of population aging. This increase is likely due to changing patient expectations, as well as advances in perioperative care. However, patients, age and pre-existing comorbidities remain significant predictors of adverse postoperative outcome [1-16].

In particular, elderly patients appear to accrue excess morbidity and mortality following gallbladder surgery [16]. Acknowledging acute complicated calculous biliary disease (ACCBD) as a common set of clinical problems presented to general surgeons, the Cohort Studies Group of the European Society for Trauma and Emergency Surgery (ESTES) set out to capture real-world data on the epidemiology, and contemporary management of these patients [17, 18]. Traditional medical school teaching identifies the 6Fs (fair, fat, fertile, female, forty, and family history) as phenotypic predictors of symptomatic gallstone disease [19]. Notably, however, the cohort presenting to European emergency departments with acute complicated

2 School of Medical Sciences, Orebro University, 70281 Orebro, Sweden

3 Department of Surgery, Tallaght University Hospital, Dublin 24, Ireland

4 Clinical Epidemiology and Biostatistics, School of Medical Sciences, Orebro University, 70182 Orebro, Sweden

5 Division of Trauma and Emergency Surgery, Department of Surgery, Orebro University Hospital, 70185 Orebro, Sweden
This study was an exploratory subgroup analysis from an international, multicenter, prospective non-randomized observational cohort study, conducted according to a previously published protocol (protocol registered at ClinicalTrials.gov, \#NCT03610308). All participating centers provided local institutional review board approval or equivalent as a requirement of registration. Center and patient eligibility, as well as data capture, have been reported in previous publication [18].

The study included adult patients (over 18 years of age) presenting with acute complicated calculous biliary disease defined as one of the following diagnoses: American Association of Trauma (AAST) Severity Grade II or above acute calculous cholecystitis, choledocholithiasis, cholangitis, or biliary pancreatitis; subjected to any interventions ranging from conservative management to surgical or radiological interventions. The study excluded patients with uncomplicated biliary colic, biliary dyskinesia, or uncomplicated acute calculous cholecystitis (AAST Grade I).

\section{Statistical analysis}

Descriptive and inferential statistical analyses were performed using Stata 15.1 (StataCorp LLC, College Station, TX, USA) and the jamovi project (www.jamovi.com, 2019) utilizing the $R$ language for statistical computing. Effect estimates are presented as odds ratios (OR) with 95\% confidence intervals and two-tailed $P$ values. An alpha significance level of 0.05 was used throughout. Measures of central tendency were presented as mean $[ \pm$ standard deviation (SD); median, interquartile range (IQR)]. 
Table 1 Patient Demographics, comparing those under and over 65 years

\begin{tabular}{|c|c|c|c|c|}
\hline & $<65$ years & $\geq 65$ years & Total & $p$ value \\
\hline Included patients $n(\%)$ & $153(45.3)$ & $185(54.7)$ & $338(100)$ & \\
\hline Age, years, mean (SD) & $47(12)$ & $79(8.0)$ & $65(18)$ & $<0.001$ \\
\hline Sex, Female $n(\%)$ & $91(59.5)$ & $91(49.2)$ & $182(53.8)$ & 0.075 \\
\hline Charlson Comorbidity Index, median (IQR) & $1.0(0.0-2.0)$ & $4.0(4.0-6.0)$ & $3.0(1.0-5.0)$ & $<0.001$ \\
\hline Age-adjusted Charlson Comorbidity Index, median (IQR) & $3.0(1.0-4.0)$ & $9.0(7.0-11.0)$ & $6.0(3.0-9.0)$ & $<0.001$ \\
\hline$B M I(k g / m 2)$, mean $(S D)$ & $29.6(7.2)$ & $27.3(6.2)$ & $28.3(6.8)$ & 0.002 \\
\hline$A S A, n(\%)$ & & & & $<0.001$ \\
\hline 1 & $53(35.1)$ & $9(4.9)$ & $62(18.6)$ & \\
\hline 2 & $74(49.0)$ & $75(41.2)$ & $149(44.7)$ & \\
\hline 3 & $18(11.9)$ & $77(42.3)$ & $95(28.5)$ & \\
\hline 4 & $6(4.0)$ & $21(11.5)$ & $27(8.1)$ & \\
\hline Diagnosis, $n(\%)$ & & & & 0.065 \\
\hline Cholecystitis & $68(44.4)$ & $86(46.5)$ & $154(45.6)$ & \\
\hline Gallstone pancreatitis & $40(26.1)$ & $31(16.8)$ & $71(21.0)$ & \\
\hline CBD stone & $25(16.3)$ & $36(19.5)$ & $61(18.0)$ & \\
\hline Cholangitis & $16(10.5)$ & $31(16.8)$ & $47(13.9)$ & \\
\hline Mirizzi syndrome or bilioenteric fistula & $4(2.6)$ & $1(0.5)$ & $5(1.5)$ & \\
\hline AAST Cholecystitis Grade, $n(\%)$ & & & & 0.048 \\
\hline 1 & $0(0.0 \%)$ & $0(0.0 \%)$ & $0(0.0 \%)$ & \\
\hline 2 & $58(85.3 \%)$ & $66(76.7 \%)$ & $124(80.5 \%)$ & \\
\hline 3 & $4(5.9 \%)$ & $15(17.4 \%)$ & $19(12.3 \%)$ & \\
\hline 4 & $6(8.8 \%)$ & $3(3.5 \%)$ & $9(5.8 \%)$ & \\
\hline 5 & $0(0.0 \%)$ & $2(2.3 \%)$ & $2(1.3 \%)$ & \\
\hline Grade 3 or higher & $10.0(14.7 \%)$ & $20.0(23.3 \%)$ & $30.0(19.5 \%)$ & $0.183^{1}$ \\
\hline AAST Pancreatitis Grade, $n(\%)$ & & & & 0.542 \\
\hline 1 & $31(81.6)$ & $26(83.9)$ & $57(82.6)$ & \\
\hline 2 & $6(15.8)$ & $4(12.9)$ & $10(14.5)$ & \\
\hline 3 & $0(0.0)$ & $1(3.2)$ & $1(1.4)$ & \\
\hline 4 & $1(2.6)$ & $0(0.0)$ & $1(1.4)$ & \\
\hline
\end{tabular}

\section{Outcome measure}

Outcomes were compared between patients aged under and $\geq 65$ years and, within the $\geq 65$ group, between patients who underwent operative or non-operative management. The primary outcome measure was index admission surgical treatment by cholecystectomy. Secondary outcome measures included the total LOS, the postoperative LOS (in whole days), postoperative and 30-day mortality rates, and a post-discharge rehabilitation requirement.

\section{Results}

\section{Participating centers}

Following an open call for participation by ESTES in May 2018, 38 centers expressed interest in participating. Of those, 25 centers completed the local ethics approval process and enrolled patients in the study. These centers came from 9 countries: Austria, Italy, Ireland, Romania, Spain, Sweden, Portugal, the United Kingdom, and the USA [18].

\section{Patient demographics and clinical characteristics}

Three-hundred and thirty-eight individual patients admitted between October 1 and October 312018 were enrolled in the study and followed up until 120 days following admission.

Over half $(54.7 \%)$ of the study cohort were age 65 years or older. The mean age in the $\geq 65$ years group was $79 \pm 8$ years compared to $47 \pm 12$ years in the $<65$ years group $(p=0.001)$. There was no statistically significant difference in sex between the groups (59.5\% vs. $49.2 \%, p=0.075)$. As depicted in Table 1, patients in the $\geq 65$ years group had more comorbidities measured by their Charlson Comorbidity Index (CCI), were less fit for 
Table 2 Surgical, endoscopic and radiologic intervention and outcomes, comparing those under and over 65 years

\begin{tabular}{|c|c|c|c|c|}
\hline & $<65$ years & $\geq 65$ years & Total & $\mathrm{p}$ value \\
\hline Surgical Intervention, n (\%) & $99(64.7)$ & $70(37.8)$ & $169(50.0)$ & $<0.001$ \\
\hline \multicolumn{5}{|l|}{ Surgical Approach, $n(\%)$} \\
\hline Laparoscopic & $86(86.9)$ & $56(80.0)$ & $142(84.0)$ & $0.153^{1}$ \\
\hline Laparoscopic converted to open & $5(5.0)$ & $9(12.9)$ & $14(8.2)$ & $0.070^{1}$ \\
\hline Open & $8(8.1)$ & $5(7.1)$ & $13(7.6)$ & $0.909^{1}$ \\
\hline \multicolumn{5}{|l|}{ Type of surgery, $n(\%)$} \\
\hline Cholecystectomy & $98(98.9)$ & $67(95.7)$ & $165(97.6)$ & $0.399^{1}$ \\
\hline Subtotal cholecystectomy & $1(1.1)$ & $3(4.3)$ & $5(2.9)$ & $0.180^{1}$ \\
\hline Admission to Surgery (days), median (IQR) & $2.0(1.0-6.2)$ & $1.0(0.0-3.5)$ & $2.0(0.0-5.5)$ & 0.057 \\
\hline Endoscopy Intervention, n (\%) & $35(22.9)$ & $63(34.1)$ & $98(29)$ & 0.024 \\
\hline Admission to Endoscopy (days), median (IQR) & $4.0(2.0-5.0)$ & $6.5(2.2-11.0)$ & $5.0(2.0-8.0)$ & 0.009 \\
\hline IR Intervention, n (\%) & $11(7.2)$ & $15(8.1)$ & $26(7.7)$ & 0.752 \\
\hline Admission to IR (days), median (IQR) & $2.0(0.0-6.0)$ & $2.5(1.2-9.2)$ & $2.0(0.5-7.0)$ & 0.358 \\
\hline Postoperative LOS (days), median (IQR) & $3.0(2.0-6.0)$ & $5.0(3.8-9.2)$ & $4.0(3.0-7.0)$ & 0.002 \\
\hline Total LOS (days), median (IQR) & $7.0(4.0-9.0)$ & $7.5(5.0-14.0)$ & $7.0(4.0-10.0)$ & 0.039 \\
\hline \multicolumn{5}{|l|}{ Disposition, $n(\%)$} \\
\hline Home & $149(97.4)$ & $157(84.9)$ & $306(90.5)$ & $<0.001$ \\
\hline Mortality & $1(0.7)$ & $4(2.2)$ & $5(1.5)$ & 0.253 \\
\hline Convalescence & $3(2.0)$ & $24(13.0)$ & $27(8.0)$ & $<0.001$ \\
\hline
\end{tabular}

surgery based on their ASA score, were significantly more likely to have a history of ischemic heart disease, congestive heart failure, cerebrovascular disease, insulin-dependent diabetes mellitus, and chronic renal disease compared to patients under 65. Previous abdominal surgical history did not differ between patients under and $\geq 65$ years (37\% vs. $34 \%, p=0.487$ ) (Table 1$)$.

\section{Diagnosis}

Cholecystitis was the most common (45.6\%) diagnosis in the study cohort, followed by gallstone pancreatitis (21\%), common bile duct stone (18\%), and cholangitis (13.9\%). Five patients $(1.5 \%)$ had Mirizzi syndrome or bilioenteric fistula. There was no statistical difference in main admitting diagnosis between those under and $\geq 65$ years $(p=0.065)$ (Table 1). The incidence of cholecystitis AAST grade III and V was higher in the $\geq 65$ compared to the $<65$ years group, $17.4 \%$ vs. $5.9 \%$ and $2.3 \%$ vs. $0 \%$ ( $p=0.048)$, respectively. AAST grade IV cholecystitis was more common in the $<65$ years group $(8.8 \%$ vs. $3.5 \%, p=0.048$ ) (Table 1). There was no difference in the severity of pancreatitis between the groups based on the AAST grading (Table1).

\section{Surgical intervention}

Of the 338 patients enrolled in the study, 50\% underwent surgical intervention, while $50 \%$ had not received operative treatment by the end of the 120-day follow-up period. Patients younger than 65 were more likely to undergo index admission cholecystectomy than those $\geq 65$ years (64.7\% vs. $37.8 \%, p=0.001)$. Cholecystectomy alone was performed in $99.3 \%$ of cases [18]. The use of laparoscopy did not differ between age groups (86.9\% vs. $80.0 \%$, $p=0.153)$. Conversion occurred in $14(8.2 \%)$ cases, 5 in patients under $65(5 \%)$ and $9(12.9 \%)$ in those $\geq 65$ years of age $(p=0.070)$. A further thirteen $(7.6 \%)$ cholecystectomies were performed as open from the beginning of the procedure-eight in patients under 65 years and five in patients $\geq 65$ ( $p=0.909)$. Subtotal cholecystectomy was performed in 3 patients $\geq 65$ and 1 in under 65 years $(p=0.180)$. It was not possible to ascertain the reasons for conversion, subtotal cholecystectomy, or primary open cholecystectomy. There was a trend towards shorter time to surgery from admission in the $\geq 65$ group [days median (IQR): $1.0(0.0-3.5)$ vs. $2.0(1.0-6.2), p=0.057$ ] (Table 2).

\section{Endoscopic management}

Patients in the $\geq 65$ group underwent endoscopic evaluation and management of the common bile duct more 
frequently than younger patients, $(34.1 \%$ versus $22.9 \%$, $p=0.024)$. Endoscopic Retrograde Cholangiopancreatography (ERCP) with duct clearance and sphincterotomy was the most commonly performed procedure $(77.6 \%)$, followed by ERCP and stent placement (19.4\%), and diagnostic EUS alone $(3.1 \%)$. Of those patients undergoing ERCP, nine (9.2\%) patients experienced complications, namely post-ERCP pancreatitis in six $(6.1 \%)$ and bleeding in three $(3.1 \%)$. No procedure was complicated by perforation. Time from admission to endoscopy was significantly longer in patients over the age of 65 years compared with patients under 65 [days Median (IQR): 6.5 (2.2-11.0) vs. $4(2.0-5.0), p=0.009]$ (Table 2).

\section{Interventional radiologic management}

Interventional radiologic management of the gallbladder or common bile duct was undertaken in $26(7.7 \%)$ of patients -11 patients under the age of 65 years and 15 patients $\geq 65 \quad(p=0.752)$. Cholecystostomy was performed in $23(88.5 \%)$ of these cases, percutaneous radiologic drainage of a collection or abscess was performed in one $(3.8 \%)$ patient, and percutaneous transhepatic cholangiography was performed in two $(7.7 \%)$. No complication was recorded for patients undergoing interventional radiologic procedures. Time from admission to intervention radiology intervention did not differ between patients over the age of 65 years compared with patients under 65 [days median (IQR): 2.5 (1.2-9.2) vs. $2(0.0-6.0), p=0.358]$ (Table 2).

\section{Outcomes}

Nineteen patients $(5.6 \%)$ were admitted to ICU for organ failure during their hospital stay-10 $(6.5 \%)$ patients under 65 and $9(4.8 \%) \geq 65(p=0.506)$. Both postoperative [days median (IQR): 5.0 (3.8-9.2) vs. 3.0 (2.0-6.0), $p=0.002$ ] and total hospital length of stay [days median (IQR): 7.5 (5.0-14.0) vs. $7.0(4.0-9.0), p=0.039$ ] (irrespective of diagnosis) was longer for patients $\geq 65$ years (Table 2). Conversion to open cholecystectomy doubled the median (IQR) postoperative length of stay from 4.0 $(2.0-6.0)$ to $8.0(4.0-12.0)$ days $(p=0.006)$.

Five deaths were recorded $(1.4 \%)$ in the total cohortone $(1.4 \%)$ patient in those suffering from gallstone pancreatitis, two $(4.2 \%)$ in patients with cholangitis, and two (1.2\%) patients with acute cholecystitis, both of which had an AAST Grade IV cholecystitis. One $(0.58 \%)$ postoperative death occurred following cholecystectomy for AAST Grade IV cholecystitis. Four deaths occurred in patients $\geq 65$ (2.2\%), compared with one $(0.7 \%)$ under 65 years $(p=0.253)$. Those patients who died had a significantly higher comorbidity burden, with a median (IQR) age- adjusted CCI (aaCCI) of $12.0(11.0-12.0)$ versus 6.0 (3.0-8.0) in surviving patients $(p<0.001)$. Of the 333 patients surviving to discharge, significantly more patients $\geq 65$ years had ongoing morbidity requiring postacute convalescence or rehabilitation (13.0\%), compared with $2 \%$ under the age of $65(p<0.001)$. Postoperative complications were reported more frequently in patients over 65 compared with younger patients without statistical significance $(18.6 \%$ vs. $10.1 \%, p=0.114)$ (Table 3$)$.

\section{Demographics, management, and outcomes of the elderly subgroup}

Patient demographic and clinical characteristics in patients over 65 years of age, dichotomized into surgical or nonoperative management, are captured in Table 4. Patients who underwent cholecystectomy were younger ( $75 \pm 7 \mathrm{vs}$. $81 \pm 8$ years, $p<0.001)$, male $(64.3 \%$ vs. $42.6 \%$, $p=0.004$ ), and with fewer comorbidities [CCI median (IQR): $4.0(3.0-5.0)$ vs. $5.0(4.0-2.6), p=0.031]$. There was no difference in their fitness for surgery based on their preoperative ASA score assessment $(p=0.197)$ (Table 4). Acute cholecystitis was the most common diagnosis in the cholecystectomy group $(74.3 \%$ vs. $29.6 \%, p<0.001)$, while most non-operated patients presented with gallstone pancreatitis, common bile duct stone, or cholangitis $(69.5 \%$ vs. $25.7 \%, p<0.001)$. There was no difference in intervention radiology $(p=0.437)$ or endoscopy interventions ( $p=0.813$ ) between the cohorts (Table 5). No statistical differences in the total hospital length of stay or disposition after discharge was measured between the groups (Table 5).

\section{Discussion}

There has been a disproportionate increase in the number of older adults within the world population over the last 50 years, with the global population aged 60 years or older projected to treble to nearly 2 billion people within the first half of this century [20]. In Europe alone, almost $30 \%$ of the population is predicted to be aged 65 or over by 2050 [20]. Geriatric patients frequently undergo emergency general surgery and accrue more postoperative complications and fatal outcomes than the general population $[5,13,16]$. It is thus highly relevant to develop and guide evidence-based patient-centered decision-making around emergency surgical care [21]. ACCBD is a relatively frequent diagnosis in patients over 65 years, and while some consensus guidance exists, age is not considered to be a contraindication to operative management [26]. 
Table 3 Operative and postoperative complications in patients under and over 65 years undergoing surgical intervention

\begin{tabular}{|c|c|c|c|c|}
\hline & $<65$ years & $\geq 65$ years & Total & $p$ value \\
\hline Strasberg Classification of CBD Complication, $n(\%)$ & & & & $0.183^{1}$ \\
\hline Cystic duct leak & $2(1.3)$ & $5(2.7)$ & $7(2.1)$ & \\
\hline Lateral injury to CBD/CHD (Strasberg D) & $1(0.7)$ & $0(0.0)$ & $1(0.3)$ & \\
\hline CBD/CHD division (Strasberg E1) & $0(0.0)$ & $1(0.5)$ & $1(0.3)$ & \\
\hline Postoperative, $n(\%)$ & & & & $0.114^{1}$ \\
\hline No complication & $89(89.9 \%)$ & $57(81.4 \%)$ & $146(86.4 \%)$ & \\
\hline Abscess & $3(3.0 \%)$ & $4(5.7 \%)$ & $7(4.1 \%)$ & \\
\hline Bile duct complications & $3(3.0 \%)$ & $6(8.6 \%)$ & $9(5.3 \%)$ & \\
\hline Hemorrhage & $0(0.0 \%)$ & $1(1.4 \%)$ & $1(0.6 \%)$ & \\
\hline Wound infection & $3(3.0 \%)$ & $2(2.9 \%)$ & $5(3.0 \%)$ & \\
\hline Enterotomy & $1(1.0 \%)$ & $0(0.0 \%)$ & $1(0.6 \%)$ & \\
\hline Total & $10(10.1 \%)$ & $13(18.6 \%)$ & $23(13.6 \%)$ & \\
\hline
\end{tabular}

${ }^{1}$ Pearson's Chi-squared test

Table 4 Demographics, treatment metrics and outcomes in patients over the age of 65 years, comparing those who underwent surgical intervention or not

\begin{tabular}{|c|c|c|c|c|}
\hline & Not operated $(N=115)$ & Operated $(N=70)$ & Total $(N=185)$ & $p$ value \\
\hline Age, years, mean (SD) & $81(8)$ & $75(7)$ & $79(8.0)$ & $<0.001$ \\
\hline Sex, Female $n(\%)$ & $66(57.4 \%)$ & $25(35.7 \%)$ & $91(49.2 \%)$ & 0.004 \\
\hline Charlson Comorbidity Index, median (IQR) & $5.0(4.0-6.2)$ & $4.0(3.0-5.0)$ & $4.0(4.0-6.0)$ & 0.031 \\
\hline Age-adjusted Charlson Comorbidity Index, median (IQR) & $8.0(7.0-10.0)$ & $8.0(6.0-9.0)$ & $8.0(7.0-10.0)$ & 0.024 \\
\hline BMI $\left(\mathrm{kg} / \mathrm{m}^{2}\right)$, mean $(\mathrm{SD})$ & $27.0(5.6)$ & $28.6(5.3)$ & $27.6(5.5)$ & $0.049^{1}$ \\
\hline ASA, $n(\%)$ & & & & $0.197^{2}$ \\
\hline 1 & $1(3.1 \%)$ & $4(7.7 \%)$ & $5(6.0 \%)$ & \\
\hline 2 & $8(25.0 \%)$ & $23(44.2 \%)$ & $31(36.9 \%)$ & \\
\hline 3 & $17(53.1 \%)$ & $19(36.5 \%)$ & $36(42.9 \%)$ & \\
\hline 4 & $6(18.8 \%)$ & $6(11.5 \%)$ & $12(14.3 \%)$ & \\
\hline Diagnosis, $n(\%)$ & & & & $<0.001^{1}$ \\
\hline Cholecystitis & $34(29.6 \%)$ & $52(74.3 \%)$ & $86(46.5 \%)$ & \\
\hline Gallstone pancreatitis & $27(23.5 \%)$ & $4(5.7 \%)$ & $31(16.8 \%)$ & \\
\hline Cholangitis & $26(22.6 \%)$ & $5(7.1 \%)$ & $31(16.8 \%)$ & \\
\hline CBD stone & $27(23.5 \%)$ & $9(12.9 \%)$ & $36(19.5 \%)$ & \\
\hline Mirizzi syndrome or bilioenteric fistula & $1(0.9 \%)$ & $0(0.0 \%)$ & $1(0.5 \%)$ & \\
\hline AAST Cholecystitis Grade, $n(\%)$ & & & & $0.642^{1}$ \\
\hline 1 & $0(0 \%)$ & $0(0 \%)$ & $0(0 \%)$ & \\
\hline 2 & $26(76.5 \%)$ & $40(76.9 \%)$ & $66(76.7 \%)$ & \\
\hline 3 & $7(20.6 \%)$ & $8(15.4 \%)$ & $15(17.4 \%)$ & \\
\hline 4 & $1(2.9 \%)$ & $2(3.8 \%)$ & $3(3.5 \%)$ & \\
\hline 5 & $0(0.0 \%)$ & $2(3.8 \%)$ & $2(2.3 \%)$ & \\
\hline Grade 3 or higher & $8.0(23.5 \%)$ & $12.0(23.1 \%)$ & $20.0(23.3 \%)$ & $0.961^{1}$ \\
\hline AAST Pancreatitis Grade, $n(\%)$ & & & & $0.700^{1}$ \\
\hline 1 & $23(85.2 \%)$ & $3(75.0 \%)$ & $26(83.9 \%)$ & \\
\hline 2 & $3(11.1 \%)$ & $1(25.0 \%)$ & $4(12.9 \%)$ & \\
\hline 3 & $1(3.7 \%)$ & $0(0.0 \%)$ & $1(3.2 \%)$ & \\
\hline 4 & $0(0 \%)$ & $0(0 \%)$ & $0(0 \%)$ & \\
\hline
\end{tabular}

${ }^{1}$ Linear Model ANOVA ${ }^{2}$ Trend test for ordinal variables 
Table 5 Surgical, endoscopic and radiologic intervention and outcomes in patients over 65 years of age, comparing those who underwent surgical intervention or not

\begin{tabular}{|c|c|c|c|c|}
\hline & Not operated $(\mathrm{N}=115)$ & Operated $(\mathrm{N}=70)$ & Total $(\mathrm{N}=185)$ & $p$ value \\
\hline Admission to IR (days) & & & & $0.437^{1}$ \\
\hline $\mathrm{IR}, \mathrm{n}(\%)$ & $9(7.8 \%)$ & $7(10.0 \%)$ & 18 & \\
\hline Mean (SD) & $5.7(11.5)$ & $9.9(9.2)$ & $7.3(10.6)$ & \\
\hline Admission to Endoscopy (days) & & & & $0.813^{1}$ \\
\hline Endoscopy, n (\%) & $45(39.1 \%)$ & $19(27 \%)$ & 62 & \\
\hline Mean (SD) & $9.0(10.8)$ & $9.8(12.4)$ & $9.3(11.2)$ & \\
\hline \multicolumn{5}{|l|}{ Surgical Approach, $n(\%)$} \\
\hline Laparoscopic & & $55(78.6 \%)$ & & \\
\hline Laparoscopic converted to open & & $9(12.9 \%)$ & & \\
\hline Open & & $6(8.6 \%)$ & & \\
\hline \multicolumn{5}{|l|}{ Type of surgery, $n(\%)$} \\
\hline Cholecystectomy & & $66(94.3 \%)$ & & \\
\hline Subtotal cholecystectomy & & $4(5.7 \%)$ & & \\
\hline \multicolumn{5}{|l|}{ Admission to ICU (days) } \\
\hline ICU admission, n (\%) & $1(0.9 \%)$ & $8(11.4 \%)$ & $9(4.9 \%)$ & 0.004 \\
\hline Median (IQR) & $4.0(4.0$ to 4.0$)$ & $3.0(1.8$ to 8.0$)$ & $3(2$ to 8$)$ & $0.695^{1}$ \\
\hline Total Length of Stay (days) & & & & $0.538^{1}$ \\
\hline Mean (SD) & $9.3(7.6)$ & $10.0(9.3)$ & $9.6(8.3)$ & \\
\hline Median (IQR) & $7.0(5.0$ to 12.0$)$ & $7.0(5.0$ to 12.0$)$ & $7.0(5.0$ to 12.0$)$ & \\
\hline \multicolumn{5}{|l|}{ Disposition, $n(\%)$} \\
\hline Home & $94(81.7 \%)$ & $63(90.0 \%)$ & $157(84.9 \%)$ & $0.128^{1}$ \\
\hline Mortality & $3(2.6 \%)$ & $1(1.4 \%)$ & $4(2.2 \%)$ & $0.592^{1}$ \\
\hline Convalescence & $18(15.7 \%)$ & $6(8.6 \%)$ & $24(13.0 \%)$ & $0.165^{1}$ \\
\hline
\end{tabular}

${ }^{1}$ Linear Model ANOVA

As evidenced by a significantly higher CCI and ageadjusted CCI in the current study cohort, pre-existing cardiovascular, endocrine, and renal comorbidities are more frequent in older than younger patients [9-11]. While a direct correlation has yet to be studied between aaCCI and morbidity and mortality following emergency cholecystectomy, strong evidence exists supporting aaCCI as a robust predictor of poor outcomes following elective gynecologic, oncologic gastrointestinal, and emergency orthopedic surgery [22-25]. Indeed, the observed case fatality rate in our study was $2.2 \%$ in patients over 65 years, a postoperative complication occurred in $18.6 \%$, and aaCCI was positively correlated with higher mortality and complication rates.

International guidelines, which advocate for index admission cholecystectomy, make no specific recommendations for older patients [2]. In the current cohort of patients admitted for acute complicated biliary calculus disease, index admission cholecystectomy was achieved only in $37.8 \%$ cases in patients 65 years of age and older. Subgroup analysis of the over 65 years cohort detected no difference in fitness for surgery by anesthesia assessment (as measured by ASA classification score) or difference in severe cholecystitis incidence (AAST Grade 3-5). However, the non-operative group was found to be older. This finding is of particular importance since other gallstone complications (e.g., gallstone pancreatitis, common bile duct stone with or without concomitant cholangitis) were managed by percutaneous cholecystostomy or ERCP alone. Several studies have shown better outcomes in those who received early cholecystectomy following duct clearance for gallstone pancreatitis, and the Tokyo Guidelines (2018) advise index admission cholecystectomy in this instance $[26,27]$. A recent comparison of one-stage ERCP and cholecystectomy versus index admission ERCP with planned interval elective day-case cholecystectomy demonstrated a readmission rate over $20 \%$ in the latter group, due to complications relating to the retained gallbladder as a stone reservoir [28]. Regrettably, our current data did not report readmission rate, but given the overlap in patient populations, we would expect similar rates of disease recidivism in the non-operated cohort. However, there was no difference in postintervention complications between the cohorts. These are important factors to 
consider when deferring cholecystectomy in the elderly frail patient since another physiologic hit from recurrent disease could be devastating. Further, as a temporary measure of source control compared to cholecystectomy, percutaneous cholecystostomy has been shown to be associated with more complication and mortality in the elderly population [29]. Such interventions should be reserved for patients that fulfill the criteria for absolute contraindication for anesthesia or surgery [30].

Notably, recovery following acute illness and mainly surgical intervention may be prolonged in the elderly population, as a consequence of a loss of strength, mobility, and functional capacity [31-34]. However, there was no difference hospital length of stay, and post-discharge disposition comparing those patients over 65 years of age subjected to cholecystectomy versus their counterparts. Thus, it appears that underlying frailty, not surgical stress, might be the principal factor predicting recovery from acute illness.

The growing elderly patient population poses challenges to physicians and healthcare systems worldwide. While some risk factors, such as age and comorbidities, cannot be modified, other components of care such as multidisciplinary management in close collaboration with gerontology colleagues, time to the operating room and early physiologic optimization have been shown to improve outcomes. To that end, The American College of Surgeons has launched a geriatric verification program for hospitals and the American Geriatrics Society and the American College of Surgeons have issued joint guidelines on optimal care of the geriatric surgical patient based on analysis of retrospective administrative NSQIP data [35, 36]. Finally, with the linkage between higher hospital and surgeon volume of emergency surgical cases and improved outcome, especially in geriatrics, designated centers or indeed acute surgical service reorganization at a local level should be considered for this patient population in the future [37-39].

\section{Conclusion}

Although this study is limited by its intention and design as a descriptive study, granular 'real world' data illustrate the challenges faced by elderly patients with AACBD. Excess morbidity, mortality, length of postoperative hospitalization, and a greater need for rehabilitation are seen in these patients. Guidelines considering age and comorbidities, routine use of prognostic tools and frailty indices in mitigating risk or pre-rehabilitation, and anticipating the requirement for enhanced supports in this patient cohort is warranted.
Acknowledgements The authors would like to thank the European Society for Trauma and Emergency Surgery for facilitating this collaborative effort. In particular, thanks are due to Dr Jorge Pereira, Mr Michael Sugrue and Prof. Andreas Shamiyeh of the Emergency Surgery Committee of ESTES.

Authors' contributions GAB, AEG, YC and SM conceived the study, analyzed the data and wrote the manuscript. All study collaborators sought local ethics approval, provided the anonymous patient-level data and per protocol are listed as PubMed-indexed authors.

Funding Open access funding provided by Örebro University.

Data availability The datasets used and analyzed during the current study are available from the corresponding author on reasonable request. This prospective, observational, multicenter audit was conducted in line with a pre-specified protocol which was registered with ClinicalTrials.gov (Trial \# NCT03610308).

\section{Declaration}

Conflict of interest The authors declare no conflicts of interest.

Ethical approval All 25 participating centers (see Supplemental Table of Collaborators) provided local institutional review board approval or equivalent as a requirement of registration. No patient consent was sought since the current study was purely observational and did not change the medical course of any patient. All data were irrevocably de-identified at source when uploaded to the secure study database.

Consent for publication All authors consent to publication. This manuscript is not currently under review elsewhere.

Open Access This article is licensed under a Creative Commons Attribution 4.0 International License, which permits use, sharing, adaptation, distribution and reproduction in any medium or format, as long as you give appropriate credit to the original author(s) and the source, provide a link to the Creative Commons licence, and indicate if changes were made. The images or other third party material in this article are included in the article's Creative Commons licence, unless indicated otherwise in a credit line to the material. If material is not included in the article's Creative Commons licence and your intended use is not permitted by statutory regulation or exceeds the permitted use, you will need to obtain permission directly from the copyright holder. To view a copy of this licence, visit http://creativecommons. org/licenses/by/4.0/.

\section{Appendix 1}

Collaborating Group Membership

\begin{tabular}{lll}
\hline Country & Center name & Authors \\
\hline Austria & Kepler University Clinic & Andreas Shamiyeh, Lena \\
& & Rosetti, Günter \\
& & Klimbacher, Bettina \\
& & Klugsberger \\
Ireland & Beaumont Hospital Dublin & Paul Healy, Conor Moriarty, \\
& & Colm Power, Nauar \\
& & Knightly, Arnold DK Hill
\end{tabular}




\begin{tabular}{|c|c|c|c|c|c|}
\hline Country & Center name & Authors & Country & Center name & Authors \\
\hline Ireland & $\begin{array}{l}\text { SVUH Institute for } \\
\text { Clinical Outcomes } \\
\text { Research and } \\
\text { Education, Dublin }\end{array}$ & $\begin{array}{l}\text { Desmond C Winter, Michael } \\
\text { E Kelly, Ben E Creavin, } \\
\text { Éanna J Ryan, Caoimhe C } \\
\text { Duffy }\end{array}$ & $\begin{array}{l}\text { Sweden } \\
\text { Sweden }\end{array}$ & $\begin{array}{l}\text { Jönköping Medical Center } \\
\text { Linköping University } \\
\text { Hospital }\end{array}$ & $\begin{array}{l}\text { Anna Älverdal } \\
\text { Stefan Redeen }\end{array}$ \\
\hline Ireland & $\begin{array}{l}\text { Letterkenny University } \\
\text { Hospital }\end{array}$ & $\begin{array}{l}\text { Michael Sugrue, Michael } \\
\text { Hugh Moore, Louise }\end{array}$ & Sweden & $\begin{array}{l}\text { Örebro University } \\
\text { Hospital }\end{array}$ & $\begin{array}{l}\text { Shahin Mohseni, Ahmad } \\
\text { Mohammad Ismail, } \\
\text { Rebecka Ahl }\end{array}$ \\
\hline Ireland & $\begin{array}{l}\text { Mayo University Hospital, } \\
\text { Castlebar, Mayo }\end{array}$ & $\begin{array}{l}\text { Jessica Ryan, Conor Keady, } \\
\text { Brian Fahey, Kevin L } \\
\text { McKevitt, Kevin Barry }\end{array}$ & UK & Stoke Mandeville Hospital & $\begin{array}{l}\text { Spyros Marinos, Naomi } \\
\text { Warner, Rikhil Patel, } \\
\text { Tania Magro, Romeshan } \\
\text { Sunthareswaran }\end{array}$ \\
\hline Ireland & $\begin{array}{l}\text { Saint Vincent's University } \\
\text { Hospital, Dublin }\end{array}$ & $\begin{array}{l}\text { Kevin C Conlon, Keno } \\
\text { Mentor, Andrea Kazemi- } \\
\text { Nava, Barbara Julies }\end{array}$ & UK & $\begin{array}{l}\text { Tameside General } \\
\text { Hospital }\end{array}$ & $\begin{array}{l}\text { Andrei Mihailescu, Goran } \\
\text { Pokusewski, Alexandru } \\
\text { Leopold Bubuianu }\end{array}$ \\
\hline \multirow[t]{2}{*}{ Ireland } & \multirow[t]{2}{*}{$\begin{array}{l}\text { Tallaght University } \\
\text { Hospital, Dublin }\end{array}$} & \multirow{2}{*}{$\begin{array}{l}\text { Paul F Ridgway, Dara O } \\
\text { Kavanagh, Mark } \\
\text { Donnelly, Cathleen } \\
\text { McCarrick, Umair } \\
\text { Muhammad, Tara M } \\
\text { Connelly, Paul C Neary }\end{array}$} & UK & $\begin{array}{l}\text { Wrightington, Wigan and } \\
\text { Leigh NHS Foundation } \\
\text { Trust }\end{array}$ & $\begin{array}{l}\text { Corneliu Dimitriu, Marius } \\
\text { Paraoan }\end{array}$ \\
\hline & & & UK & Worthing Hospital & $\begin{array}{l}\text { Arjun Desai, Katie Jones, } \\
\text { Makhosini Mlotshwa, } \\
\text { Kenny Ross, Simon }\end{array}$ \\
\hline Italy & $\begin{array}{l}\text { Fondazione Policlinico } \\
\text { Universitario “A. } \\
\text { Gemelli" IRCCS }\end{array}$ & $\begin{array}{l}\text { Sabina Magalina, Valerio } \\
\text { Cozza, Antonio LaGreca, } \\
\text { Daniele Gui }\end{array}$ & & & $\begin{array}{l}\text { Lambracos, Yegor } \\
\text { Tryliskyy }\end{array}$ \\
\hline Italy & Policlinico San Pietro, & Alessia Malagnino, Mauro & USA & Marshfield Clinic & Daniel C. Cullinane \\
\hline
\end{tabular}

Italy Clinica Chirurgica, Trieste Alan Biloslavo, Natasa University Hospital, Samardzic, Stefano Trieste, Italy Fracon, Davide Cosola, Nicolò de Manzini

Portugal Centro Hospitalar de Trás- Urânia Fernandes, Paulo os-montes e Alto Douro Avelar, Rita Marques, Ana Sofia Esteves, André Marçal, Carina Gomes

Portugal Centro Hospitalar Cova de Daniela Machado, Tobias Biera, Covilha

Teles, Sofia Neves, Miguel Semiao, Rui Cunha

Portugal Centro Hospitalar Tondela Jorge Pereira, Júlio Viseu Constantino, Milene Sá, Carlos Casimiro

Romania St. Spiridon Emergency Universitary Hospital, Iasi

Lidia Ionescu, Roxana Livadariu, Ludmila Stirbu, Radu Danila, Daniel Timofte, Bogdan Astefaniei

Spain Hospital Urduliz

Aitor Landaluce Olavarria, Begoña Estraviz Mateos, Jaime Gonzalez Taranco, David Gomez, Jon Barrutia, Julio Zeballos

$\begin{array}{ccc}\text { Spain } & \text { University Hospital } & \text { Dieter Morales Garcia, Ana } \\ & \text { Lozano Najera, Erik } \\ \text { Valdecilla" } & \text { Gonzalez Tolaretxipi } \\ \text { Spain } & \text { Hospital Virgen del Rocío } & \text { Luis Tallon-Aguilar, José } \\ & & \text { Pintor-Tortolero, } \\ & \text { Alejandro Sanchez- } \\ & \text { Arteaga, Virginia Duran- } \\ & \text { Muñóz Cruzado, Violeta } \\ & \text { Camacho-Marente, José } \\ & \text { Tinoco-Gonzalez }\end{array}$

\section{References}

1. Garcés-Albir M, Martín-Gorgojo V, Perdomo R et al (2019) Acute cholecystitis in elderly and high-risk surgical patients: is percutaneous cholecystostomy preferable to emergency cholecystectomy? J Gastrointest Surg Official J Soc Surg Alimentary Tract. https://doi.org/10.1007/s11605-019-04424-5

2. Pisano M, Ceresoli M, Cimbanassi S et al (2019) 2017 WSES and SICG guidelines on acute calcolous cholecystitis in elderly population. World J Emerg Surg 14:10

3. Desserud K, Veen T, Søreide K (2016) Emergency general surgery in the geriatric patient. Brit J Surg 103:e52-e61

4. Chambers D. Anaesthesia in the elderly (2019) Anaesth Intensive Care Medicine. . Epub ahead of print. DOI: https://doi.org/10. 1016/j.mpaic.2019.10.001

5. Lidsky M, Thacker J, Lagoo-Deenadayalan S et al (2012) Advanced age is an independent predictor for increased morbidity and mortality after emergent surgery for diverticulitis. Surgery 152:465-472

6. Gaitanidis A, Mikdad S, Breen K, et al. (2020)The Emergency Surgery Score (ESS) accurately predicts outcomes in elderly patients undergoing emergency general surgery. Am J Surg. Epub ahead of print. DOI: https://doi.org/10.1016/j.amjsurg.2020.02. 017.

7. Ikeuchi H, Uchino M, Matsuoka $H$ et al (2014) Prognosis following emergency surgery for ulcerative colitis in elderly patients. Surg Today 44:39-43

8. Cao Y, Bass GA, Ahl R, et al. (2020) The importance of P-POSSUM for predicting mortality after emergency laparotomy in geriatric patients. BMC Medical Informatics and Decision Making. Article in Press

9. Lin J-X, Huang Y-Q, Xie J-W et al (2019) Age-adjusted Charlson Comorbidity Index (ACCI) is a significant factor for predicting survival after radical gastrectomy in patients with gastric cancer. Bmc Surg 19:53 
10. Kahl A, du Bois A, Harter P et al (2017) Prognostic value of the age-adjusted Charlson comorbidity index (ACCI) on short- and long-term outcome in patients with advanced primary epithelial ovarian cancer. Ann Surg Oncol 24:3692-3699

11. St-Louis E, Iqbal S, Feldman LS et al (2015) Using the ageadjusted Charlson comorbidity index to predict outcomes in emergency general surgery. J Trauma Acute Care 78:318-323

12. Kristjansson SR, Rønning B, Hurria A et al (2012) A comparison of two pre-operative frailty measures in older surgical cancer patients. J Geriatr Oncol 3:1-7

13. Khan S, Chua H, Hirubalan P et al (2016) Association between frailty, cerebral oxygenation and adverse post-operative outcomes in elderly patients undergoing non-cardiac surgery: an observational pilot study. Indian J Anaesth 60:102-107

14. Lin H, Watts J, Peel N et al (2016) Frailty and post-operative outcomes in older surgical patients: a systematic review. Bmc Geriatr 16:157

15. Richards S, Frizelle F, Geddes J et al (2018) Frailty in surgical patients. Int J Colorectal Dis 33:1657-1666

16. McKay A, Katz A, Lipschitz J (2013) A population-based analysis of the morbidity and mortality of gallbladder surgery in the elderly. Surg Endosc 27:2398-2406

17. Bass GA, Gillis AE, Cao Y et al (2020) Self-reported and actual adherence to the Tokyo guidelines in the European snapshot audit of complicated calculous biliary disease. Bjs Open 4:622-629

18. Bass GA, Gillis AE, Cao Y, et al. (2020) Patterns of prevalence and contemporary clinical management strategies in complicated acute biliary calculous disease - an ESTES 'snapshot audit' of practice, to European Journal of Trauma and Emergency Surgery. EJTES. 2020.Article in Press.

19. Bass G, Gilani SNS, Walsh TN (2013) Validating the 5Fs mnemonic for cholelithiasis: time to include family history. Postgrad Med J 89:638

20. World Population Ageing: 1950-2050 Available from: http:// www.un.org/esa/population/ publications/worldageing 19502050/ pdf/80chapterii.pdf

21. Dahlberg J, Dahl V, Forde R et al (2019) Lack of informed consent for surgical procedures by elderly patients with inability to consent: a retrospective chart review from an academic medical center in Norway. Patient Saf Surg 13:24

22. Kreitz TM, Tarazona D, Padegimas EM, et al. Comparison of Short term Outcomes After Lumbar Fusion Between an Orthopedic Specialty Hospital and Tertiary Referral Center. Spine. 2018;Publish Ahead of Print:NA

23. Beck D, Raikin S, Pedowitz D, et al. Total Ankle Arthroplasty. Foot Ankle Orthop. 2017;2:2473011417S000117

24. Moodley Y (2016) Outcome-specific Charlson comorbidity indices for predicting poor inpatient outcomes following noncardiac surgery using hospital administrative data. Med Care 54:1082-1088

25. Reinstatler L, Klaassen Z, Madi R et al (2017) Comorbidity Is a competing factor for disease recurrence postnephrectomy. Southern Med J 110:369-374

26. Mayumi T, Okamoto K, Takada T, et al. (2018) Tokyo Guidelines 2018 management bundles for acute cholangitis and cholecystitis. J Hepato-bil-pan Sci. Epub ahead of print 2017. DOI: https://doi.org/10.1002/jhbp.519
27. Mueck KM, Wei S, Pedroza C et al (2019) Gallstone pancreatitis: admission versus normal cholecystectomy-a randomized trial (Gallstone PANC Trial). Ann Surg 270:519-527

28. Bass GA, Pourlotfi A, Donnelly M, et al. (2021) Bile Duct Clearance and Cholecystectomy for Choledocholithiasis: Definitive Single-Stage Laparoscopic Cholecystectomy with IntraOperative Endoscopic Retrograde Cholangiopancreatography (ERCP) versus Staged Procedures. J Trauma Acute Care Surg.;Publish Ahead of Print . Epub ahead of print 2020. DOI: https://doi.org/10.1097/ta.0000000000002988

29. Schlottmann F, Gaber C, Strassle PD, et al. (2019) Cholecystectomy Vs. Cholecystostomy for the Management of Acute Cholecystitis in Elderly Patients. $J$ Gastrointest Surg. 23:503-509.

30. Gurusamy KS, Rossi M, Davidson BR (2013) Percutaneous cholecystostomy for high-risk surgical patients with acute calculous cholecystitis. Cochrane Db Syst Rev. 8:CD007088

31. Theou O, Rockwood M, Mitnitski A et al (2012) Disability and co-morbidity in relation to frailty: how much do they overlap? Arch Gerontol Geriat 55:e1-e8

32. Rockwood K, Song X, MacKnight C et al (2005) A global clinical measure of fitness and frailty in elderly people. Can Med Assoc J 173:489-495

33. Evaluation of a frailty index based on a comprehensive geriatric assessment in a population based study of elderly Canadians. Cochrane Central Register Control Trials Central.;2007 . Epub ahead of print 2018. DOI: https://doi.org/10.1002/central/cn00562699

34. Launay-Savary M, Mathonnet M, Theissen A et al (2017) Are enhanced recovery programs in colorectal surgery feasible and useful in the elderly? A systematic review of the literature. J Visc Surg 154:29-35

35. Berian JR, Zhou L, Hornor MA et al (2017) Optimizing surgical quality datasets to care for older adults: lessons from the American college of surgeons NSQIP geriatric surgery pilot. J Am Coll Surgeons 225(702-712):e1

36. Turrentine FE, Zaydfudim VM, Martin AN, et al. (2020) Association of Geriatric-Specific Variables with 30-Day Hospital Readmission Risk of Elderly Surgical Patients: a NSQIP Analysis. J Am Coll Surgeons. . Epub ahead of print 2020. DOI: https:// doi.org/10.1016/j.jamcollsurg.2019.12.032

37. Mehta A, Varma S, Efron DT et al (2019) Emergency general surgery in geriatric patients. J Trauma Acute Care 86:189-195

38. Ogola GO, Crandall ML, Richter KM et al (2018) High-volume hospitals are associated with lower mortality among high-risk emergency general surgery patients. J Trauma Acute Care 85:560-565

39. McCann A, Sorensen J, Nally D et al (2020) Discharge outcomes among elderly patients undergoing emergency abdominal surgery: registry study of discharge data from Irish public hospitals. Bmc Geriatr 20:72

Publisher's Note Springer Nature remains neutral with regard to jurisdictional claims in published maps and institutional affiliations. 